GH98 - PO - 037

\author{
INDONESIAN PETROLEUM ASSOCIATION \\ Proceedings of the Gas Habitats of SE Asia and Australasia Conference
}

\title{
SPECTRAL ANALYSIS OF WIRELINE LOGS - AN INNOVATIVE APPROACH TO ANALYZING FOSSIL DEPOSITIONAL SYSTEMS
}

\author{
Nio Swie Djin* \\ Herman Soediono** \\ Antoine A.H. Wonders***
}

\begin{abstract}
Pattern recognition in wireline $\log$ analysis has benefited remarkably little from the enormous advances made in the development of technology which is applied to analysis of all kinds of waves. Wireline log correlation is often still a matter of the skillful intuitive recognition of log patterns. A new, objective way of looking at wireline logs is proposed, with emphasis on the cyclic nature of the wireline log trace. The theoretical background of this innovative way of looking at wireline logs is based on the sound assumption that sediments, as fossil depositional systems, inherit cyclicity from cyclic climatic change at various wave lengths. The ultimate interpretation of results of computed spectral analysis remains dependant on the geological skills of the interpreter, with strong emphasis on a sound understanding of depositional systems. It does not, however, rely on the largely non-quantifiable intuitive skills of the individual geologist in correlating logs.
\end{abstract}

For the purpose of the new method, wireline log traces are considered to be composite sine waves, the components of which can be found by maximum entropy spectral analysis. Intervals in the log trace with similar component waves showing little or gradual change, are separated by short intervals at which the component waves change rapidly. The rate of change can be expressed as a number, the prediction error. Points on the wireline log trace with maximum prediction error often represent stratigraphic horizons with sequence stratigraphic significance. These can be transformed, by

* Enres International b.v. - Huis Ter Heide, The Netherlands

** P.T. Geoservices - Bandung, Indonesia

*** StrataData Ltd. - U.K. mathematical integration of the prediction error curves, into extremes which we call Cyclic Interval Boundaries (CIB's). These may represent sequence boundaries and maximum flooding surfaces.

Results of spectral analysis of wireline logs are in the depth domain, but these changes are thought to be driven by cyclic variations in the time domain, more specifically by cyclic climatic change. The detected frequencies are in the Milankovitch band (20-400 Ka) to third and second order Vailian type cycles (1-25 Ma). The Milankovitch frequencies, especially the longer and shorter Eccentricity terms, turn out to be particularly useful in sediments varying in age from Neogene to Carboniferous. Minor hiatuses, often not detectable by conventional age dating, can be recognised and quantified by counting the number of missing short-term cycles at reservoirs, which is an order of magnitude more precise than conventional methods. Originally designed for clastic systems, the method has been successfully applied to carbonate reservoirs as well, leading to a stratigraphic resolution of $20 \mathrm{Ka}$.

Early applications of spectral analysis of wireline logs include studies on important non-marine sandstone gas reservoirs in NW Europe. Extremely detailed reservoir sand correlations could be made. Shaly intervals could be classified as representing laterally extensive major climatic optima or as minor parasequence cycle boundaries. The results had major implications for the interpretation of shales as potential pressure barriers and intra-formational seals. Currently, other studies are in progress on oil and gas reservoirs of Tertiary, Mesozoic and younger Palaeozoic age. Spectral analysis software is being incorporated in seismic work stations for direct comparison of stratigraphic cycles and seismic facies. 